\section{Influenza vaccine efficacy}

I am writing in response to a recent news article ${ }^{1}$ published in CMAJ. The lack of efficacy of this year's vaccine preparation is often used as an argument against vaccination. Although the match between the vaccine H3N2 strain and the circulating H3N2 wildtype may not be optimum, we must recognize that influenza seasons often have two strains. In addition to the recent $\mathrm{H} 3 \mathrm{~N} 2$ epidemic activity in Canada, we will likely see a second (and unpredictable) wave, such as influenza B, this season. Therefore, the efficacy of the 2014-2015 vaccine will only be fully measurable at the end of May, 2015.

\section{Nevio Cimolai MD}

Children's \& Women's Health Centre of British Columbia, Vancouver, BC

\section{Reference}

1. Vogel L. Vaccinate or mask pays off. CMAJ 2015 187:19.

CMAJ 2015. DOI:10.1503/cmaj.115-0021

\section{Better treatment for depression}

How can the recent $C M A J$ editorial on depression recognize the grief that followed Robin William's suicide and yet be so despairing by stating that depression deserves better treatment? ${ }^{1}$ The tragedy is not just that so many people have depression or that despite good treatments some will lose their battle, but also that our society does not make treatment universally accessible.

During a roundtable discussion of the Canadian Depression Research and Intervention Network in the spring of 2011, then Minister of Labour Lisa Raitt argued for a better strategy on mental health in the workplace. Raitt detailed her experience with depression after the birth of her second child. Her general practitioner convinced her to take antidepressants, and she has recovered well. Hers is but one example.

Large transnational studies show that increased sales of antidepressants are associated with a significant decrease in suicide rates in adults and a lesser one in adolescents. ${ }^{2,3}$ The opposite effect occurred when black-box warnings appeared on antidepressants for adolescents: there was an increase in suicide in the following year. ${ }^{4}$ There was also a decrease in the treatment of depression by physicians and in the number of prescriptions for antidepressants. If we interpret this through the perspective of the general theory of psychotherapy and apply it to antidepressant treatment, the black-box warnings sent a despairing message to physicians that treatment may be more dangerous than beneficial, and to patients and families, that treatment may not work.

A recent population survey by Statistics Canada on mental health and well-being assessed the perceived needs for care: the need for medication was largely met, but the need for psychotherapy was not. ${ }^{5}$ Medication is easily accessible in Canada, with many provinces providing universal coverage. However, this is not the case for psychotherapy. In a publicly managed health care system like Canada's, what is not insured is simply not accessible.

Australia and Great Britain have increased insured access to psychotherapy services. In Australia, psychotherapy prescribed by a general practitioner and delivered by an accredited psychotherapist is reimbursed through the Australian physicians' billing insurance plan. The result has been an increase, from $37 \%$ to $47 \%$, in the treatment of common mental disorders. ${ }^{6}$ Studies on the effectiveness of psychotherapy in Australia and Britain show that, on average, patients will require five to six sessions and that the effect sizes will be large (circa 1). For instance, $70 \%$ of patients at intake will meet criteria for moderate depression, while only $20 \%$ will do so after treatment. ${ }^{7,8}$

What message should Canadian physicians give to their patients with depression? First, there are effective treatments for depression and second, what is medically required should be insured to provide improved access.
I invite Canadian physicians to join coalitions to ensure equitable access to treatments, like the Graham Boeckh Foundation (www.grahamboeckh foundation.org).

\section{Alain Lesage MD MPhil}

Institut universitaire en santé mentale de Montréal, Montréal, Que.

\section{References}

1. Patrick K. Depression deserves better treatment. CMAJ 2014;186:1043

2. Gunnell D, Frankel S. Prevention of suicide: aspirations and evidence. BMJ 1994;308:1227-33.

3. Ludwig J, Marcotte DE. Anti-depressants, suicide, and drug regulation. J Policy Anal Manage 2005 24:249-72.

4. Katz LY, Kozyrskyj AL, Prior HJ, et al. Effect of regulatory warnings on antidepressant prescription rates, use of health services and outcomes among children, adolescents and young adults. [published erratum in CMAJ 2008;178:1466] CMAJ 2008;178:1005-11.

5. Sunderland A. Findlay LC. Perceived need for mental health care in Canada: results from the 2012 Canadian Community Health Survey: Mental Health. Ottawa: Statistics Canada; 2013. Available: www.statcan.gc.ca/pub/82-003-x/2013009/article /11863-eng.htm

6. Whiteford HA, Buckingham WJ, Harris MG, et al. Estimating treatment rates for mental disorders in Australia. Aust Health Rev 2014;38:80-5.

7. Richards DA, Suckling R. Improving access to psychological therapies: phase IV prospective cohort study. Br J Clin Psychol 2009;48:377-96.

8. Pirkis J, Ftanou M, Williamson M, et al. Australia's Better Access initiative: an evaluation. Aust N Z J Psychiatry 2011:45:726-39.

CMAJ 2015. DOI:10.1503/cmaj.115-0022

Patrick's recent editorial ${ }^{1}$ on the need for more awareness for major depressive disorder forgets to mention the sorry case of major depressive disorder's ugly stepsister, bipolar disorder.

An estimated $40 \%$ of people with major depressive disorder actually have bipolar disorder. The typical patient with bipolar disorder waits 10 years or more from first symptoms to correct diagnosis (it is difficult to diagnose a condition that is rarely acknowledged).

Even in the tragic case of Robin Williams, the public conversation was focused entirely on depression and substance abuse. Not a word about bipolar disorder.

The correct diagnosis is important because treatment for the two disorders is entirely different. Antidepressants can actually make bipolar disorder worse.

It is my firm conclusion that every 
person diagnosed with major depressive disorder should be reinterviewed, specifically to rule out the diagnosis of bipolar disorder. Think of all the lives, jobs and families that would be saved by incorporating this one "functional inquiry" into our diagnostic process.

Patrick ${ }^{1}$ referenced the recent research indicating that in major depressive disorder, antidepressants may be no better than placebo. Perhaps their results would be more reliable if those "confounding" patients with bipolar disorder were split off from the crowd.

\section{Barry Rich MD}

Retired physician and bipolar disorder survivor, North Vancouver, BC

\section{Reference \\ 1. Patrick K. Depression deserves better treatment CMAJ 2014; 186:1043.}

CMAJ 2015. DOI:10.1503/cmaj.115-0023

Thank you to Patrick for her recent editorial $^{1}$ on depression. Her statement that "the fact that we don't have widely accessible and effective treatments for depression is a serious problem" is an understatement. Canada is capable of doing much better.

The way forward is through:

- a massive effort to make evidencesupported behavioural treatments accessible to all Canadians

- better integration of primary care with mental health care

- more research into strategies to improve behavioural treatment outcomes such as mindfulness to improve the outcomes of cognitive behavioural therapy

- new models for delivery of mental health care such as the Mood Disorders Association of BC Psychiatric Urgent Care Program to replace the inefficient and costly private-practice model that so many psychiatrists use ${ }^{2}$

- more research into why some individuals with depression drop out of treatment or do not respond (each individual with depression needs a thorough psychiatric assessment to identify comorbid conditions such as anxiety or personality disorder that contribute to drop out or treatment failure if not addressed)

- boosting community programs.
The need is urgent and action is required at all levels: federally, provincially and locally.

\section{Richard E. Hibbard MD}

Alberta Health Services, Edmonton, Alta.

\section{References}

1. Patrick K. Depression deserves better treatment. CMAJ 2014:186:1043.

2. Remick RA, Araki Y, Bruce R, et al. The Mood Disorders Association of British Columbia Psychiatric Urgent Care Program: A preliminary evaluation of a suggested alternative model of outpatient psychiatric care. Can J Psychiatry 2014;59:220

CMAJ 2015. DOI:10.1503/cmaj.115-0024

\section{Penicillin VK oral suspension}

In response to Gilles and colleagues research article, ${ }^{1}$ I would like to point out that regardless of the adverse effects associated with amoxycillin use, it is among the most commonly used antibiotics for respiratory infection in Canada. It is often prescribed as a substitute for penicillin $\mathrm{VK}$ in the treatment of presumed or established streptococcal pharyngitides. There may be some justification for amoxycillin or cephalexin use in select streptococcal pharyngitides, but these antibiotics carry a larger spectrum of antimicrobial activity than penicillin and, as such, raise greater concern for driving antibiotic resistance.

Underlying this dilemma, is the lack of availability for oral penicillin VK suspension for pediatric use in Canada. The oral suspension (in contrast to the available tablet form) is an orphan drug and would need to be compounded specially. Greater availability of penicillin VK oral suspension could play a small role in diminishing antibiotic resistance in the community and in diminishing some of the adverse effects attributed to the larger spectrum amoxycillin.

\section{Nevio Cimolai MD}

Children's \& Women's Health Centre of British Columbia, Vancouver, BC

\section{Reference}

1. Gillies M, Ranakusuma A, Hoffmann T, et al Common harms from amoxicillin: a systematic review and meta-analysis of randomized placebocontrolled trials for any indication. CMAJ 2015; 187:21-31.

CMAJ 2015. DOI:10.1503/cmaj.115-0025

\section{Letters to the editor}

Letters have been abbreviated for print See www.cmaj.ca for full versions and competing interests.

\section{Corrections \\ Figure caption}

The caption for Figure 2B in an article ${ }^{1}$ that appeared in the Nov. 18, 2014, issue of $C M A J$ is incorrect. It should read: Non-necrotizing granulomas were detected on axillary node biopsy (hematoxylin-eosin, original magnification $\times 200$ ).

\section{Reference}

1. Steriade C, Shumak SL, Feinstein A. A 54-year-old man with hallucinations and hearing loss. CMAJ 2014; $186: 1315-8$

CMAJ 2015. DOI:10.1503/cmaj.115-0026

\section{Forum}

A letter ${ }^{1}$ that appeared in the Feb. 3, 2015, issue of CMAJ contains an error. A forum mentioned in the letter was hosted by the World Heart Federation and the Canadian Academy of Health Sciences. It was not hosted by the World Health Organization.

\section{Reference}

1. Campbell N, L'Abbe MR, McHenry EW. Too much focus on low-quality science? [letter] CMAJ 2015;187:131-2.

CMAJ 2015. DOI:10.1503/cmaj.115-0027 